\title{
A Study on the Influencing Factors of Changchun Residents' Rural Tourism Behavior Intention
}

\author{
Chunyan Wang ${ }^{1, a}$ and Qinglan Luo ${ }^{1, b}$ \\ ${ }^{1}$ College of Business Administration, Jilin Engineering Normal University, Changchun, China \\ asunny203@126.com, b541012329@qq.com
}

\begin{abstract}
Keywords: Rural tourism; Behavior intention; Influencing factors; Theory of planned behavior (TPB); Changchun City
\end{abstract}

\begin{abstract}
This study proposes hypotheses according to the theory of planned behavior, refers to previous research results and designs the questionnaire of Changchun residents' rural tourism behavior intention. 213 valid questionnaires are collected by means of network survey and field investigation. By using SPSS17.0, the correlation analysis for sample data is done and hypothesis is tested. The conclusions of this research: attitude, subjective norm and perceived behavioral control have significant positive influence on the rural tourism behavior intention.
\end{abstract}

\section{Introduction}

Rural tourism started in France in 1855, and it has entered the participation development stage with society, economy, agriculture, tourism and other disciplines after 100 years of development. Marketing theory, consumer behavior theory, customer' value theory has been gradually involved in the study of rural tourism. The domestic research on rural tourism started in the middle of 1990s, it mainly focus on the concept of rural tourism, the dynamic mechanism of rural tourism and new rural construction, rural tourism attractions planning and layout etc.. Reviewing the relevant research results, it is found that most of the researches are macro qualitative research on rural tourism managers or operators, and that the research result of rural tourists' behavior is rare. In recent years, relying on the superior ecological environment and rich tourism resources, Changchun develops rural tourism and integrates the characteristics of modern agriculture, including accommodation, leisure sports, fruit picking, customs and festival etc.. Changchun residents like this new way of traveling with short distance and low cost, that is the future direction of the tourism consumption in Changchun. For the further implementation of farmers' entrepreneurship, improvement of agricultural income and rural prosperity, it is necessary to fully recognize and understand the influence factors of rural tourism behavior intention.

\section{Theoretical Model Construction}

The theory and Model of planned behavior is an important tool to study the behavior of the individual from the inner perspective, can effectively explain and predict the behavior of the individual intention [1-2], and has been applied to psychology, education, diet, sports, tourism and other research fields by domestic and foreign scholars. According to the theory of planned behavior, behavior is determined by intention, and behavioral attitude, subjective norm and perceived behavior control are the important factors that influence individual intention. In tourism research, the theory of planned behavior by domestic and foreign scholars has been applied to the study of behavior intention of leisure tourism, low-carbon tourism and other fields. A large number of researches have demonstrated that the theory of planned behavior has a good explanatory and predictive power to the behavioral intention of tourists [3-6]. Therefore, based on the theory of planned behavior, this study takes three behavioral perception factors as the core variables [7-8], which are rural tourism attitude, subjective norm and perceived behavior control. 


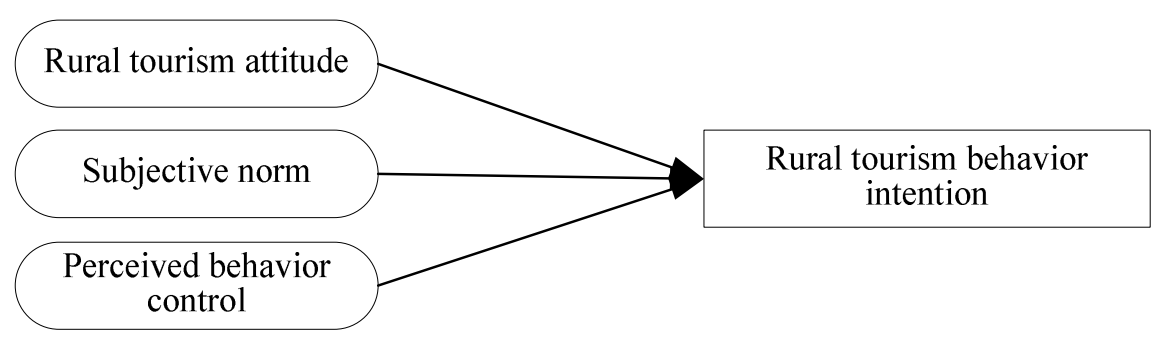

Figure 1. Finite The influence Factors Model of rural tourism behavior intention

\section{Research Hypothesis}

Behavioral perception factors include three dimensions [9]: Rural Tourism attitude, subjective norm and perceived behavior control.

Rural Tourism Attitudes. The attitude of rural tourism is the positive or negative view of the individual to the rural tourism, which reflects the individual's enthusiasm for participating in rural tourism [10]. In the theory of planned behavior, behavioral attitude is a positive or negative views held by the individual for an act, which reflects the degree of individual's feelings of affection. Affective attitude and instrumental attitude are the main influencing factors. According to the theory of planned behavior, the individual's attitude toward a certain behavior directly affects their behavior intention, the greater the positive attitude towards a certain behavior, the stronger the intention to take the behavior, and the weaker contrarily. Therefore, this paper puts forward the research hypothesis 1:

H1: Rural Tourism attitude has a significant positive impact on rural tourism behavior intention.

Subjective Norms. The subjective norm refers to the influence of individual friends or his organization on individual rural tourism decision-making, when he decides whether to participate in the rural tourism. There is not an independent individual, who has certain social character. He will refer to the opinions of surrounding family and friends while deciding whether to perform a behavior, also may therefore to change its behavior intention. According to the theory of planned behavior, there is a direct link between the individual's subjective norms and the emergence of behavioral intention, the stronger the subjective norm, the stronger the behavioral intention. Therefore, this paper puts forward the research hypothesis 2 :

$\mathrm{H} 2$ : The subjective norms of rural tourism have a significant positive impact on rural tourism behavior intention.

Perceived Behavioral Control. Perceived behavioral control refers to the perception and expectation of the degree of difficulty in carrying out the rural tourism, which is influenced by the tourism experience and external factors. If people feel in rural tourism can get huge benefits, while their relatives, friends and other important reference objects is higher on the term of rural tourism decision support degree, and they have the necessary resources, such as more time, money and skills, so their probability of participation is greater in rural tourism. Through empirical researches, most scholars have proved that the theory of planned behavior, which is based on the perceived behavioral control variables, is more effective in explaining the intention [2]. Therefore, this paper puts forward the research hypothesis 3 :

H3: Perceived behavioral control of rural tourism has a positive impact on rural tourism behavior intention.

\section{Empirical Analysis and Hypothesis Testing}

Sample Descriptive Statistical Analysis. The survey started from early July 2016 to the end of September 2016, to conduct research on the Changchun residents through the network questionnaire and field interviews, issued a total of 245 questionnaires were excluded, fill out 32 unqualified, the effective recovery rate was $86.9 \%$. 
In this study, SPSS17.0 software was used to analyze the gender, age, occupation, education level, monthly average income and marital status of the residents in Changchun City. Female effective sample respondents $(54.9 \%)$ of the proportion is slightly larger than the male $(45.1 \%)$. From the age distribution of the sample, there were 45 people and 78 people under 24 years old and the age of $25 \sim 34$ year, accounted for $21.2 \%$ and $36.6 \%$ respectively, shows that the respondents are mainly young and middle-aged. From a professional point of view, the occupation is more comprehensive, which accounted for a large proportion of employees and students, respectively, $34.7 \%$ and $29.1 \%$, followed by state organs or institutions staff, accounting for $14.6 \%$. In the sample, the education level of the respondents mainly concentrated in the undergraduate and master's degree and above, accounting for $40.4 \%$ and $28.6 \%$ respectively. From the monthly average income distribution of the survey sample, the respondents are 65 people whose income from RMB 3000 to RMB 6000, accounting for the maximum of $30.5 \%$, the other levels are also distributed, its distribution is more balanced and reasonable. From the point of the marriage condition, the total of unmarried people is 97 people, accounting for $45.5 \%$ in the total sample. Therefore, the characteristics of the overall sample are workers and students below 35 years old, who have received higher education and are mainly unmarried people.

According to the survey sample, the survey results are consistent with the Changchun population distribution of the overall situation, the development level of social economy, culture and education in Changchun. Thus, the selected samples are representative, the survey results can reflect the rural tourism behavior intention characteristics of Changchun residents accurately and objectively.

Reliability and Validity Analysis. In this study, the Cronbach coefficient is used to judge the level of the reliability, the higher the reliability value, the higher the reliability of the measurement tools, the more the data can reflect the real situation. In this study, Cronbach's $\alpha>0.7$, indicating that this data has high reliability and can be used. As shown in Table 1, the Cronbach's $\alpha$ of all variables in this study are above 0.7 , indicating that all the items in the scale can reflect the actual situation of rural tourism, and the reliability of the scale is good. The variables table of KMO value and Sig. value of Bartlett sphere test, the KMO values of each variable are more than 0.5 in the scale of behavior perception, respectively $0.803,0.784,0.828$ and 0.705 , and Sig. is less than 0.01 . Therefore, it can carry on the factor analysis of the four variables. The results of factor analysis are shown in Table 1, which is consistent with the design of the questionnaire.

Table 1 Main Research Variables and the reliability and validity analysis

\begin{tabular}{|l|l|l|}
\hline Research variables & $\begin{array}{l}\text { Cronbach's } \\
\text { Alpha }\end{array}$ & KMO \\
\hline Rural Tourism Attitudes & 0.821 & 0.803 \\
\hline subjective norms & 0.857 & 0.784 \\
\hline Perceived behavioral control & 0.809 & 0.828 \\
\hline rural tourism behavior intention & 0.827 & 0.705 \\
\hline
\end{tabular}

Correlation Analysis. Correlation analysis can only describe the degree of closeness between variables, and can not determine the causal relationship between variables. This study is based on the bivariate correlation analysis method, using the SPSS17.0 software to analyze the relationship between each pair variables. In order to verify the rationality of the theoretical framework, this study analyzes the relationship between rural tourism behavior intention and its influencing factors by Person correlation analysis. The results of two-tailed test: the rural tourism behavior intention has a significant positive correlation with rural tourism attitude $(\mathrm{r}=0.552, \mathrm{P}<0.01)$, subjective norm $(1=0.584, \mathrm{p}<0.01)$, perceived behavioral control $(\mathrm{r}=0.519, \mathrm{p}<0.01)$.

Regression Analysis and Hypothesis Test Results. Taking the variables of behavior perception factors as independent variables, the rural tourism behavior intention as the dependent variable, and using stepwise regression method, the results are shown in Table 2. 
Table 2 The regression analysis results of behavioral perception factors and rural tourism behavior intention

\begin{tabular}{|c|c|c|c|c|c|c|c|c|c|c|}
\hline \multirow[t]{2}{*}{ Model } & \multirow[t]{2}{*}{ Variable } & \multicolumn{2}{|c|}{$\begin{array}{c}\text { Nonstandard } \\
\text { coefficients }\end{array}$} & \multirow{2}{*}{$\begin{array}{c}\text { Standardized } \\
\text { beta } \\
\text { coefficients }\end{array}$} & \multirow[t]{2}{*}{$\mathrm{t}$} & \multirow[t]{2}{*}{ Sig. } & \multirow[t]{2}{*}{$\triangle \mathrm{R}^{2}$} & \multirow[t]{2}{*}{$\mathrm{F}$} & \multirow[t]{2}{*}{ VIF } & \multirow[t]{2}{*}{ D-W } \\
\hline & & B & SEM & & & & & & & \\
\hline \multirow[b]{2}{*}{1} & Constant & 0.733 & 0.247 & & 3.130 & 0.002 & \multirow[b]{2}{*}{0.337} & \multirow[b]{2}{*}{108.993} & & \\
\hline & $\begin{array}{c}\text { Subjective } \\
\text { norm }\end{array}$ & 0.744 & 0.071 & 0.548 & 10.440 & 0.000 & & & 1.000 & \\
\hline \multirow{3}{*}{2} & Constant & -.0222 & 0.272 & & -0.816 & 0.415 & \multirow{3}{*}{0.447} & \multirow{3}{*}{86.743} & & \\
\hline & $\begin{array}{c}\text { Subjective } \\
\text { norm }\end{array}$ & 0.543 & 0.072 & 0.426 & 7.535 & 0.000 & & & 1.223 & \\
\hline & $\begin{array}{c}\text { Rural } \\
\text { tourism } \\
\text { attitudes }\end{array}$ & 0.437 & 0.067 & 0.370 & 6.547 & 0.000 & & & 1.223 & \\
\hline \multirow{4}{*}{3} & Constant & -0.379 & 0.278 & & -1.361 & 0.175 & \multirow{4}{*}{0.458} & \multirow{4}{*}{60.677} & & \multirow{4}{*}{2.136} \\
\hline & $\begin{array}{c}\text { Subjective } \\
\text { norm }\end{array}$ & 0.478 & 0.077 & 0.375 & 6.221 & 0.000 & & & 1.420 & \\
\hline & $\begin{array}{l}\text { Rural } \\
\text { tourism } \\
\text { attitudes }\end{array}$ & 0.362 & 0.074 & 0.306 & 4.885 & 0.000 & & & 1.534 & \\
\hline & $\begin{array}{c}\text { Perceived } \\
\text { behavioral } \\
\text { control }\end{array}$ & 0.188 & 0.083 & 0.1508 & 2.265 & 0.025 & & & 1.718 & \\
\hline
\end{tabular}

Note: Dependent variable is rural tourism behavior intention.

As can be seen from Table 2, the variance inflation factor (VIF) is the maximum value of 1.718 , Durbin-Watson value of 2.136, so there is no multicollinearity, sequence correlation and other issues. At the same time, the results of the regression analysis of behavioral perception factors and rural tourism behavior intention showed that subjective norm, rural tourism attitude and perceived behavior control were significant at the corresponding significant level. According to the regression equation, the subjective norm, rural tourism attitude and perceived behavior control positively influence the rural tourism behavior intention, and the regression coefficients were $0.478,0.362$ and 0.188 respectively. $\mathrm{H} 1, \mathrm{H} 2$ and $\mathrm{H} 3$ passed the test.

\section{Conclusions}

The results of this study show that rural tourism attitude, subjective norm and perceived behavior control significantly influence the rural tourism behavior intention of residents in Changchun. From the regression analysis, we can see that the subjective norm has the most significant influence on the rural tourism behavior intention, the second is the rural tourism attitude, and the perceived behavior control is the weakest. This is not consistent with the previous research conclusions of most researchers, Arimitage and Conner (2001) believe that the subjective norms focus on the pressure of public opinion and the positive guidance of the relevant groups, the impact on behavioral intentions is weak. Most of the empirical studies have proved that behavioral attitude is the most important factor affecting the formation of behavioral intention. This may be related to China's situation and the development of rural tourism in the actual situation. Due to the influence of collectivism, the surrounding people have a great influence on the individual behavior of residents, so subjective norm has the most profound influence on individual behavior intention.

Subjective norms affect rural tourism behavior intention by the rural tourism behavior and rural tourism attitude of their family members, friends, teachers, classmates or colleagues and other 
important reference groups. If the surrounding important groups often participate in the rural tourism or support individual participation in rural tourism, the individuals will feel the psychological pressure and external obstruction is relatively smaller, he will probably be inclined to participate in rural tourism. The impact of rural tourism attitude on rural tourism behavior intention depends on individual emotion and cognition of rural tourism. On the one hand, from the perspective of rural complex, if the individual think that rural tourism is the embodiment of life with largely interesting in it, the probability and frequency of participating rural tourism will be greater; on the other hand, from the function of rural tourism, if the individual believe that rural tourism can promote rural development or can feel the different way of life, which have a positive perception of the rural tourism, they also have a positive influence on their rural tourism behavior intention. The influence of perceived behavioral control on rural tourism behavior intention depends on the individual's control beliefs and perceived convenience. If individuals believe that their own physical condition or ability is better, the stronger their control beliefs is, the greater positive impact on the rural tourism behavior intention is; if individuals believe that they have more money, time, information and other resources, the greater the convenience involved in rural tourism, and the greater the possibility of participation in rural tourism.

Therefore, subjective norm, rural tourism attitude and perceived behavior control are important factors affecting rural tourism behavior intention.

\section{Research Limitations and Prospects}

Because the economic conditions, personal energy, knowledge level and research ability is limited, there are some problems in this study, such as a single research method, the poor sample data and so on. It is necessary for scholars to do further research in the follow-up study.

\section{Acknowledgements}

This work was financially supported by Jilin Provincial Planning Office of Philosophy and Social Science Fund (No.2016B101) and the Research and Development Project of Jilin Engineering Normal University.

\section{References}

[1] M. Fishbein and I. Ajzen: Belief, Attitude, Intention and Behavior: An Introduction to Theory and Research (Trans Addison-Wesley, Boston 1975).

[2] I. Ajzen: Organizational Behavior and Human Decision Processes, Vol. 50 (1991) No.2, p.179-211.

[3] I. Ajzen and B.L. Driver: Journal of Leisure Research, Vol. 24 (1992) No.3, p.207-224.

[4] H.M. Li: A Study on the Formation Mechanism of Rural Tourism Behavior Intention-Based on the Theory of Planned Behavior (Ph.D., Zhejiang University, China 2007), p.144.

[5] S. Fan: The Studies on Influential Mechanism of Leisure Tourism Behavioral Intention Based on the Theory of Planned Behavior (Ph.D., Hunan Normal University, China 2011), p.56.

[6] Z. Hong: The Research on the Leisure Tourism Customer Behavioral Intentions Based on the Theory of Planned Behavior (Ph.D., Chongqing University of Technology, China 2013), p.43.

[7] F.Y. Chen and L.C. Tian: Tourism Management, Vol. 51 (2015) No.10, p.263-281.

[8] M. Ma and F.Y. Chen: A Study on the eWOM Communication (Trans Economic Science Press, China 2014). 
[9] C.Y. Wang: The Influence of Electronic Word-of-Mouth on the Decision-making of Online Travel Bookin (Xi'an, China, July 4-6, 2016). Vol. 1, p.934-937.

[10] Q.Q. Guo, S.F. Hu and H.B. Zhu: East China Economic Management, Vol. 28 (2013) No.12, p.167-172. 